\title{
Development of porous lamellar poly(L-lactic acid) scaffolds by conventional injection molding process
}

\author{
Satyabrata Ghosh $^{\mathrm{a}, \mathrm{b}}$, Júlio C. Viana ${ }^{\mathrm{c}}$, Rui L. Reis ${ }^{\mathrm{a}, \mathrm{b}}$, João F. Mano ${ }^{\mathrm{a}, \mathrm{b}, *}$ \\ a 3B's Research Group - Biomaterials, Biodegradables and Biomimetics, University of Minho, Campus de Gualtar, 4710-057 Braga, Portugal \\ ${ }^{\mathrm{b}}$ IBB - Institute for Biotechnology and Bioengineering, PT Government Associated Laboratory, Braga, Portugal \\ ${ }^{\mathrm{c}}$ IPC - Institute for Polymers and Composites, University of Minho, Campus de Azurém, 4800-058 Guimarães, Portugal
}

Received 23 August 2007; received in revised form 10 January 2008; accepted 6 March 2008

Available online 18 March 2008

\begin{abstract}
A novel fabrication technique is proposed for the preparation of unidirectionally oriented, porous scaffolds by selective polymer leaching from lamellar structures created by conventional injection molding. The proof of the concept is implemented using a 50/ 50 wt. \% poly(L-lactic acid)/poly(ethylene oxide) (PLLA/PEO) blend. With this composition, the PLLA and PEO blend is biphasic, containing a homogeneous PLLA/PEO phase and a PEO-rich phase. The two phases were structured using injection moldinginto welldefined alternating layers of homogeneous PLLA/PEO phase and PEO-rich phase. Leaching of water-soluble PEO from the PEO-rich phase produces macropores, and leaching of phase-separated PEO from the initially homogeneous PLLA/PEO phase produces micropores in the lamellae. Thus, scaffolds with a macroporous lamellar architecture with microporous walls can be produced. The lamellae are continuous along the flow direction, and a continuous lamellar thickness of less than $1 \mu \mathrm{m}$ could be achieved. Porosities of 57-74\% and pore sizes of around 50-100 $\mu \mathrm{m}$ can be obtained using this process. The tensile elastic moduli of the porous constructs were between 580 and $800 \mathrm{MPa}$. We propose that this organic-solvent-free method of preparing lamellar scaffolds with good mechanical properties, and the reproducibility associated with the injection moldingtechnique, holds promise for a wide range of guided tissue engineering applications. (C) 2008 Acta Materialia Inc. Published by Elsevier Ltd. All rights reserved.
\end{abstract}

Keywords: PLLA; PEO; Lamellar; Scaffold; Injection molding

\section{Introduction}

Each tissue or organ has its own characteristic architectural organization, which is closely associated with its physiological functions. Some specific tissues, such as bone, tendon, ligaments, spinal cord, peripheral nerve, ureter and intestine, have tubular or lamellar architectures. The repair of such tissues remains an intractable problem due to their poor capacity for natural regeneration. Tissue engineering strategies have great potential in the biological and functional regeneration of such tissues. In general, the growth of nerve cells is highly random and does not extend

\footnotetext{
* Corresponding author. Address: 3B's Research Group - Biomaterials, Biodegradables and Biomimetics, University of Minho, Campus de Gualtar, 4710-057 Braga, Portugal. Tel.: +351 253604497.

E-mail address: jmano@dep.uminho.pt (J.F. Mano).
}

through the lesion site to the host tissue. A better strategy is to physically guide the linear growth of axons across a site of injury. This allows retention of the original architecture of regenerating axons across the lesion site and increases the probability of achieving total functional recovery. The essential steps for engineering such strategies are the development of biomimetic and anisotropically oriented scaffolds consistent with the morphology of the natural skeleton of host tissues. In general, the materials of these temporary porous scaffolds are either of natural and synthetic biodegradable polymers [1-5]. Synthetic polymers have design flexibilities in terms of material composition, processability, control over macro- and microstructures, and mechanical properties [3]. Poly( $\alpha$-hydroxy acids) including poly(lactic acid), poly(glycolic acid) and their co-polymers are the widely accepted biodegradable synthetic polymers for tissue engineering applications. 
A number of processing techniques based on textile technologies, thermally induced phase separation, solvent casting/particulate leaching, fiber templating, melt extrusion and combinations of the above techniques have been used for the preparation of multi-tubular and simple tubular structures. Hollow conduit-like constructs can be fabricated by melt-based processing techniques such as extrusion of polymer/salt followed by leaching of salt [6]; radial alignment of internal pores across a hollow tube by spinning a polymer suspension followed by freeze drying and sublimation [7]; formation of tubular scaffolds by rolling freeze-dried films into the form of a tube [8]; bonding of non-woven polymer meshes wrapped around a mandrel and spraying a polymer solution onto them [9]; or formation of hollow fabric tubes by knitting of prefabricated yarns followed by dipping in solution, freezing and sublimation [10]. The multitubular porous scaffolds can also be prepared by phase-separation techniques, e.g. (i) freezing of polymer solution and sublimation of solvent $[11,12]$; (ii) freezing polymer/solvent with a uniaxial temperature gradient followed by sublimation of solvent [13]; (iii) injecting polymer suspension into a prefabricated multiple channel mold followed by sublimation of solvent $[14,15]$; (iv) freeze-drying with a uniaxial thermal gradient [16-18]; (v) fiber templating technique [19-21]; and (vi) solution coating and gas foaming by porogen decomposition [22]. Scaffolds prepared by the freeze-drying process are limited to thin constructs and the dense outer wall of the scaffolds may not allow interaction between the cells in the lumen and the surrounding tissue. Moreover, the dense outer walls may prevent scar tissue from invading into the scaffolds and suppress tissue regeneration. The permeability of the tubular wall is an important requirement of such scaffolds as it facilitates the supply of oxygen and nutrients and the removal of metabolic waste substances. Moreover, the use of organic solvents in most of these fabrication processes and the potential toxicity of these solvents has already been reviewed [23].

Three-dimensional porous scaffolds can also be produced from selective dissolution of a polymer from blends such as poly(L-lactic acid) (PLLA)/polystyrene, PLLA/

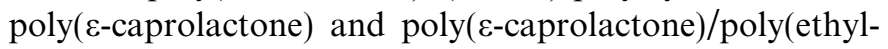
ene oxide) (PEO) [24-26]. Lee and Kim have demonstrated that a layered structure could also be produced by injection moldinga low interfacial tension, partially miscible polymer blend [27]. Injection moldingis a versatile, efficient and highly reproducible process, capable of fast production of complex geometric shapes with tight dimensional tolerances. Injection moldinghas previously been used to prepare scaffolds by compounding polymer with a blowing agent [28]. In that case sphere-shaped pores were obtained. In this work, we intend to fabricate anisotropically oriented PLLA scaffolds by injection moldinga blend of PLLA and PEO. PEO is a thermoplastic and water-soluble polymer. Moreover, PEO is biocompatible and is currently used in biomedical applications [29]. PEO has been used in this study as a porogen to obtain porous structures.
Most polymer blends are immiscible because of unfavorable interactions and the small increase in entropy upon blending. In an immiscible blend, the constitutive polymers are immiscible throughout the composition range due to the high interfacial tension and poor adhesion between the phases. In a miscible blend, however, the constitutive polymers are miscible over a wide range of compositions due to specific molecular interactions. In a partially miscible blend, a small part of one blend component is dissolved in the other component. With increased fraction of the minor phase, the system becomes biphasic and both blended phases are homogeneous [30].

A polymer pair tends to be miscible if the difference in solubility parameters is less than $0.5\left(\mathrm{cal} \mathrm{cm}^{-3}\right)^{1 / 2}[31]$. The solubility parameter is defined as $(\mathrm{CED})^{1 / 2}$, where CED is the cohesive energy density. The solubility parameters of PLLA and PEO are 10.1 and $9.9 \pm 1\left(\mathrm{cal} \mathrm{cm}^{-3}\right)^{1 / 2}$, respectively [31,32], and the closeness of these values indicates that the miscibility of PLLA and PEO is thermodynamically favorable. The glass transition temperatures $\left(T_{\mathrm{g}}\right)$ of pure PLLA and pure PEO are 61 and $-54^{\circ} \mathrm{C}$, respectively. The miscibility is supported by the detection of a single glass transition temperature in between the $T_{\mathrm{g}} \mathrm{s}$ of the pure polymers [33].

In this paper, we describe an original approach to the fabrication of anisotropically oriented porous scaffolds using a conventional melt-based injection moldingtechnique. More specifically, different layered structures were obtained by varying the injection moldingprocessing conditions of a $50 / 50 \mathrm{wt} . \%$ PLLA/PEO blend. The porous constructs were produced by swelling the compact specimens in water followed by aqueous dissolution of water-soluble PEO. The steps describing the fabrication of the unidirectionally oriented porous scaffolds are summarized in Fig. 1. The hypothesis is that this methodology could be a route to fabricate unidirectionally oriented porous scaffolds. We investigated the effect of melt processing temperature and injection flow rate on the morphology of the porous structures observed by scanning electron microcopy. The effects of processing conditions on swelling behavior, porosity and mechanical properties were also studied.

\section{Materials and methods}

\subsection{Materials}

A high stereoregular PLLA from Cargill Dow LLC, USA was used in this study. PLLA was estimated to have an L-lactide content of $99.6 \%$ based on its specific optical rotation in chloroform using an AA-1000 Polarimeter [34]. The PLLA had $\bar{M}_{n}=69,000$ and polydispersity of 1.73 as determined by gel permeation chromatography (Shimadzu LC10A, Japan) in chloroform with the standard of polystyrene. The PEO was Polyox WSR N-10, $\bar{M}_{n}=100,000$, from Dow Chemical Company, USA. A $50 / 50$ wt.\% blend of PLLA and PEO was used in this study. 

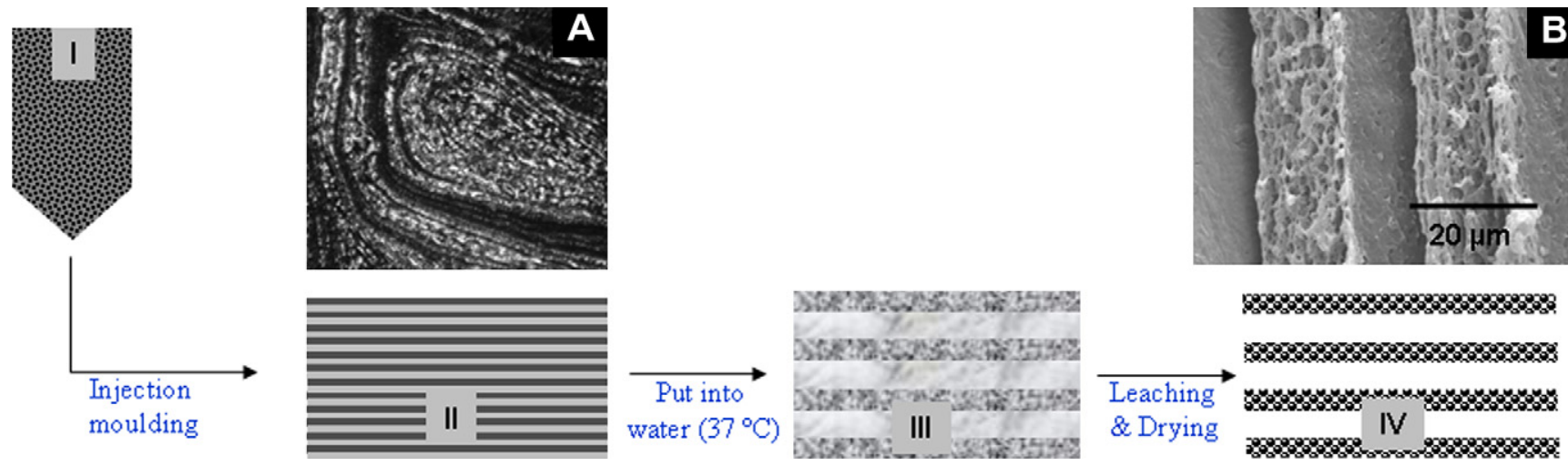

Fig. 1. Scheme for preparing the porous lamellar scaffolds using a conventional injection molding process. The 50/50 wt.\% PLLA and PEO was compounded in a tumbler mixer in solid form and put into the hopper (I). The lamellar structure was developed by injection molding the blend above the melting temperature of PLLA and PEO, and the morphology was maintained by quenching at $5{ }^{\circ} \mathrm{C}$ (II). The molded specimens were immediately immersed in water at $37{ }^{\circ} \mathrm{C}$ and the blend swelled in water (III). The porous lamellar scaffolds (IV) were obtained by aqueous leaching of water-soluble porogen. The optical micrograph (A) shows the lamellar structure of the compact injection molded specimen and the SEM micrograph shows the porous lamellar architecture (B).

\subsection{Experimental}

\subsubsection{Injection molding}

The injection molded specimens were dumbbell-shaped tensile bars of $60 \mathrm{~mm}$ length, with a constant rectangular cross-section of $4 \times 2 \mathrm{~mm}^{2}$ and a reference length of $20 \mathrm{~mm}$. They were molded in an ENGEL T 45 machine (ES-200/45 HL-V). PLLA granules and PEO powder were pre-dried at $50{ }^{\circ} \mathrm{C}$ for $4 \mathrm{~h}$ in a vacuum oven. Prior to injection molding, PLLA and PEO were extensively mixed at room temperature in a rotating-drum tumbler mixer. The processing parameters that were kept constant are shown in Table 1. The injection moldingprocessing parameters that were varied are shown in Table 2 .

\subsubsection{Swelling of lamellar structures in water}

Following their ejection from the mold, the injected specimens were immediately immersed in deionized water at $37^{\circ} \mathrm{C}$. The compact specimens swelled in water at $37^{\circ} \mathrm{C}$. The supernatant water was changed every $8 \mathrm{~h}$. The swelling process was continued for 30 days and was monitored at 5, 10, 15, 20, 25 and 30 days. At each interval, a minimum of five specimens from each run were taken out of water. Both the wet and dry weights were

Table 1

Processing parameters that were kept constant during injection molding

\begin{tabular}{lll}
\hline Parameter & Unit & Setting \\
\hline Plasticizing speed & $\%$ & 30 \\
Back pressure & $\mathrm{MPa}$ & 1 \\
Barrel temperature $\left(165^{\circ} \mathrm{C}\right)$ & ${ }^{\circ} \mathrm{C}$ & $165-155-150-100$ \\
Barrel temperature $\left(190^{\circ} \mathrm{C}\right)$ & ${ }^{\circ} \mathrm{C}$ & $190-170-150-100$ \\
Mold temperature & ${ }^{\circ} \mathrm{C}$ & 5 \\
Injection pressure (hydraulic) & $\mathrm{MPa}$ & 15 \\
Hydraulic pressure (switch over) & $\mathrm{MPa}$ & 4 \\
Holding pressure & $\mathrm{MPa}$ & 5 \\
Holding time & $\mathrm{S}$ & 3 \\
Cooling time & $\mathrm{s}$ & 30 \\
\hline
\end{tabular}

Table 2

Processing parameters that were varied during injection molding ( $T_{\mathrm{m}}=$ melt processing temperature, $Q_{\mathrm{inj}}=$ injection flow rate)

\begin{tabular}{llc}
\hline Runs & $T_{\mathrm{m}}\left({ }^{\circ} \mathrm{C}\right)$ & $Q_{\text {inj }}\left(\mathrm{cm}^{3} \mathrm{~s}^{-1}\right)$ \\
\hline C1 & 165 & 7 \\
C2 & 165 & 56 \\
C3 & 190 & 7 \\
C4 & 190 & 56 \\
\hline
\end{tabular}

measured. No mass loss was observed after 5 days. From day 10 onwards, the dried specimens from runs $\mathrm{C} 1$ and $\mathrm{C} 2$ reached a constant weight. On the other hand, specimens from runs $\mathrm{C} 3$ and $\mathrm{C} 4$ reached a constant dried weight from day 20 onwards. On day 30, the samples were taken out from water, patted dry on adsorbent paper for $2 \mathrm{~h}$ and then dried in a vacuum oven at $40^{\circ} \mathrm{C}$ for $48 \mathrm{~h}$. The volumes of the compact and porous samples were calculated by measuring the dimensions of the dried samples. The degree of equilibrium swelling was determined volumetrically after 30 days in water using the following equation:

Degree of swelling $=\left(\frac{V_{\mathrm{s}}-V}{V}\right) \times 100$,

where $V_{\mathrm{s}}$ and $V$ are the volumes of swelled specimens and compact specimens, respectively.

\subsubsection{Rheological analysis}

Rheological characterization was performed in a parallel-plate rheometer (Paar Physica, MCR 300). The discs $(0.8 \mathrm{~mm}$ thick $\times 30 \mathrm{~mm}$ in diameter) of pure PLLA and pure PEO were prepared by compression molding at 180 and $70{ }^{\circ} \mathrm{C}$, respectively. The stress sweeps were performed at 165 and $190^{\circ} \mathrm{C}$ for PLLA and PEO to demarcate the region of linear viscoelasticity. The experiments were then carried out in dynamic mode at 165 and $190{ }^{\circ} \mathrm{C}$ (corresponding to the melt processing temperatures used in the 
injection moldingprocess) from 0.1 to $100 \mathrm{~Hz}$ in a nitrogen atmosphere.

\subsubsection{Microstructural characterization}

The morphology of the dried scaffolds was examined at room temperature using scanning electron microscopy (SEM) (Leica Cambridge S-360, UK) at $15 \mathrm{kV}$. The porous tensile bar specimens were cross-sectioned at the centre. The cross-sections were then coated with a thin gold layer using a sputter coater.

\subsubsection{Estimation of density, porosity and water uptake}

The density and porosity of the porous scaffolds were determined by measuring the dimensions and mass of the scaffolds. The apparent density $(\rho)$ of the scaffolds was calculated as $\rho=m / V$, where $m$ is the mass and $V$ is the volume of the porous scaffolds.

The porosity of the porous scaffolds was calculated as

Porosity $=\left(1-\frac{\rho}{\rho_{\mathrm{c}}}\right) \times 100$,

where $\rho_{\mathrm{c}}$ is the density of amorphous PLLA, assumed to be $1248 \mathrm{~kg} \mathrm{~m}^{-3}$ [35].

To measure the water uptake, the wet scaffolds were taken out of water, placed on an adsorbent paper for $30 \mathrm{~s}$ and then weighed. The water uptake of the porous scaffolds was calculated as

Water uptake $=\left(\frac{m_{\mathrm{wet}}-m}{m}\right) \times 100$,

where $m_{\text {wet }}$ is the weight of wet scaffold.

\subsubsection{Mechanical characterization}

The dumbbell-like porous specimens were tested in an Instron 4505 computerized universal mechanical testing machine, in tensile mode. The recommendations of ASTM Standard D638 were followed. The deformation of the specimens was measured using an extensometer. The tests were performed at a controlled room temperature of $23{ }^{\circ} \mathrm{C}$ at a test velocity of $5 \mathrm{~mm} \mathrm{~min}^{-1}$. From each condition, minimum five specimens were tested. The mechanical properties tested were the elastic modulus $(E)$, the yield stress $(\sigma)$ and the yield strain $(\varepsilon)$.

\section{Results and discussion}

\subsection{Rheological properties}

The rheological behavior of neat PLLA and PEO was studied at 165 and $190{ }^{\circ} \mathrm{C}$, corresponding to the melt processing temperature used in injection molding. As expected, the viscosities of both the polymers decreased with increasing temperature (Fig. 2).

The viscosity of PLLA was sensitive to temperature and decreased at elevated temperature. PLLA is not very sensitive to shear rate in the measured shear-rate range at both studied temperatures [36].

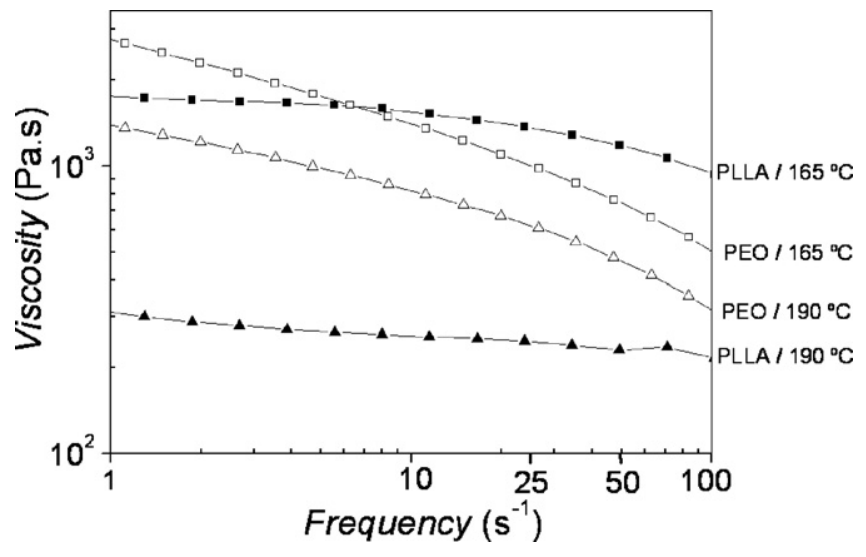

Fig. 2. Dependence of complex viscosity on angular frequency of PLLA (filled symbols) and PEO (open symbols) at $165^{\circ} \mathrm{C}$ (square symbols) and at $190{ }^{\circ} \mathrm{C}$ (triangular symbols), corresponding to the melt processing temperatures used in the injection molding process.

\subsection{Morphological development with the molten PLLA/PEO blend}

In an experiment in quiescent melt, with the particular PLLA/PEO pair used in this work, it was observed that 10 wt.\% PEO was miscible in PLLA, whereas a PEO-rich phase appears with $21 \mathrm{wt} . \%$ PEO [37]. These results are comparable with the results reported elsewhere [33], where less than $20 \mathrm{wt} . \%$ PEO formed a homogeneous PLLA/PEO phase and the homogeneity was verified from the presence of a single glass transition temperature. Therefore, it can be assumed that with the 50/50 wt.\% PLLA/PEO used in this work, the melt blend is biphasic, containing a homogeneous PLLA/PEO phase and a PEO-rich phase.

During injection molding, the biphasic blend formed the unidirectionally oriented layered structures. The schematic in Fig. 1 shows all the steps that led to the final porous constructs. All the scaffolds produced by injection molding of the blend followed by leaching of PEO exhibited unidirectionally oriented lamellae. The developed morphology was retained by fast cooling using the minimum possible mold temperature at $5{ }^{\circ} \mathrm{C}$, as the $T_{\mathrm{g}}$ of the blend was near to $0{ }^{\circ} \mathrm{C}$ [33]. After molding and upon rapid immersion in water, both the homogeneous PLLA/PEO phase and PEO-rich phase absorb water and swell. Highly oriented lamellar macropores originate from leaching of the PEO-rich phase. The micropores were produced on the pore walls through leaching of phase-separated PEO from the initially homogeneous PLLA/PEO phase.

Fig. 3a-d show the lamellar architectures of four different macroporous scaffolds produced by four different injection moldingprocessing conditions (Table 1).

The processing parameters were varied in order to assess the effect of both melt-processing temperature $\left(T_{\mathrm{m}}\right)$ and injection flow rate $\left(Q_{\text {inj }}\right)$ on the scaffold morphology. Fig. 3a $\left(T_{\mathrm{m}}=165^{\circ} \mathrm{C}, Q_{\text {inj }}=7 \mathrm{~cm}^{3} \mathrm{~s}^{-1}\right)$ presents the morphology of the oriented porous scaffold with a radial gradient to the center. Fig. $3 \mathrm{~b}\left(T_{\mathrm{m}}=165^{\circ} \mathrm{C}, Q_{\text {inj }}=56 \mathrm{~cm}^{3} \mathrm{~s}^{-1}\right)$ 

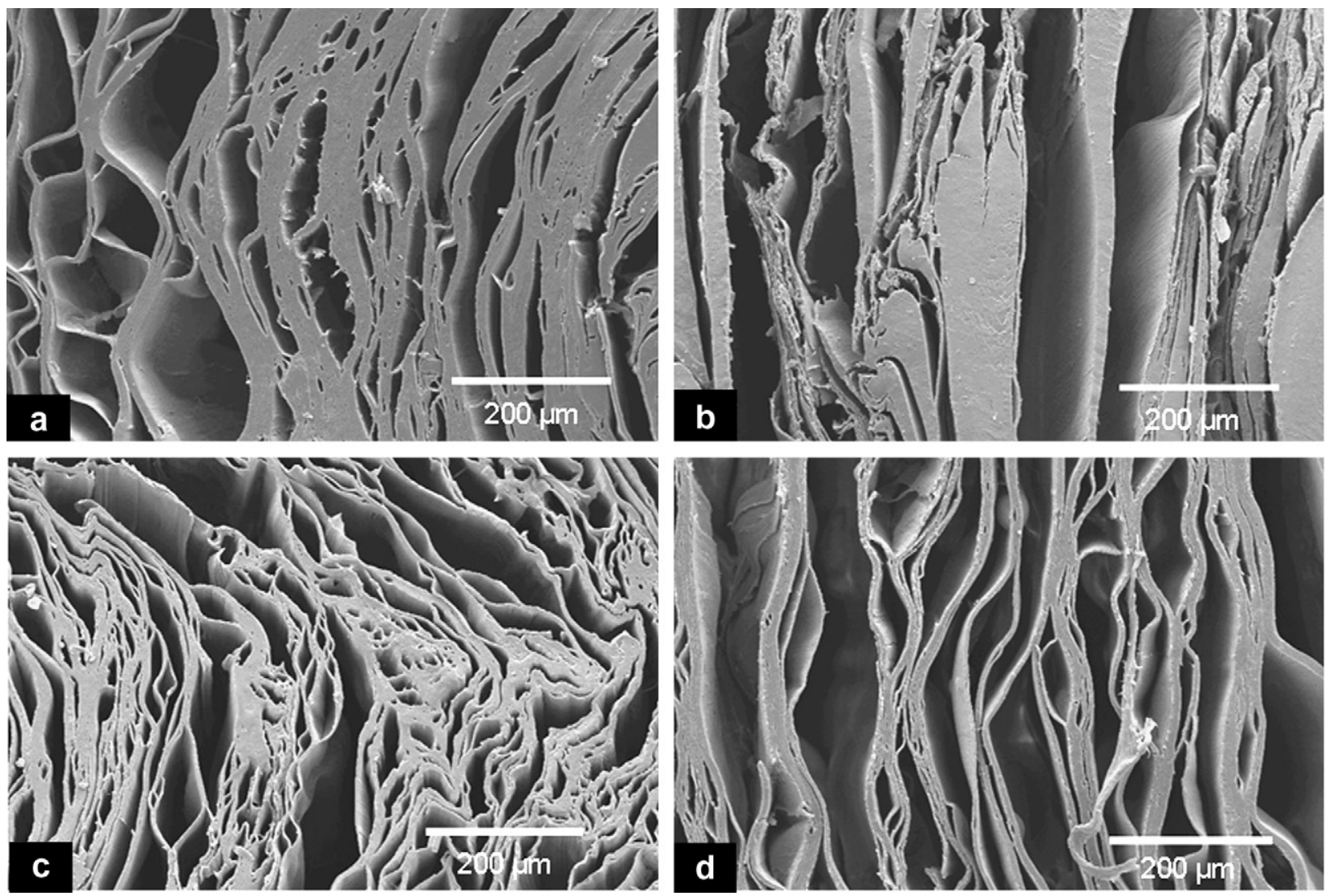

Fig. 3. SEM micrographs showing the lamellar architectures along the cross-section of PLLA scaffolds prepared from injection molding of a $50 / 50$ wt. $\%$ blend of PLLA and PEO followed by swelling and posterior leaching of porogen. (a) Melt processing temperature $=165^{\circ} \mathrm{C}$, injection flow rate $=7 \mathrm{~cm}^{3} \mathrm{~s}^{-1}$; (b) melt processing temperature $=165^{\circ} \mathrm{C}$, injection flow rate $=56 \mathrm{~cm}^{3} \mathrm{~s}^{-1}$; (c) melt processing temperature $=190{ }^{\circ} \mathrm{C}$, injection flow rate $=7 \mathrm{~cm}^{3} \mathrm{~s}^{-1}$ and (d) melt processing temperature $=190{ }^{\circ} \mathrm{C}$, injection flow rate $=56 \mathrm{~cm}^{3} \mathrm{~s}^{-1}$.

shows a lamellar architecture with a shallower gradient to the center. Fig. $3 \mathrm{c}\left(T_{\mathrm{m}}=190{ }^{\circ} \mathrm{C}, Q_{\text {inj }}=7 \mathrm{~cm}^{3} \mathrm{~s}^{-1}\right)$ shows a well-defined lamellar structure with a distinct segregation of individual layers; however, a radial concentricity was maintained. Fig. $3 \mathrm{~d} \quad\left(T_{\mathrm{m}}=190^{\circ} \mathrm{C}, \quad Q_{\text {inj }}=56 \mathrm{~cm}^{3} \mathrm{~s}^{-1}\right)$ shows a porous lamellar structure with minimum radial gradient. PLLA lamellae are thicker for specimens molded at low melt processing temperatures (Fig. 3a and b). The radial concentricity of the lamellar structures is higher for low injection flow rates (Fig. 3a and c).

The interesting feature on all the structures observed in Fig. $3 a-d$ is that the porous structures consist of only lamellae and the lamellae are integral, i.e. none of the lamellae is transformed to fibrils or droplets. The formation of a lamellar structure from partially miscible and biphasic polymer blend in a flow field is a consequence of laminar flow [38]. The 50/50 wt.\% molten PLLA and PEO mixture forms a biphasic blend containing a homogeneous PLLA/PEO phase and a PEO-rich phase. Because of the presence of PEO in both phases, the interface between two phases is practically non-existent. In the absence of interface, the morphological development of such a partially miscible biphasic system is independent of rheological parameters [38]. A partially miscible molten polymer blend behaves like a mixture of two miscible viscous liquids [39].
Under a flow field, the components of a polymer blend deform easily and produce alternating layers, characterized by lamellar thickness distribution along a cross-sectional plane [39]. The lamellar thickness of a polymer blend in laminar flow depends on total strain and viscosity of the phases [38-40]. The injection molding flow path is constant. Therefore, the morphology development of such a biphasic system is only dependent on the viscosity of the blend constituents.

The viscosity of PLLA at $165^{\circ} \mathrm{C}$ is less than the viscosity of PLLA at $190^{\circ} \mathrm{C}-$ see Fig. 2. It is intuitive that the higher-viscosity PLLA at $165^{\circ} \mathrm{C}$ deformed less and formed thicker lamellae (Fig. 3a and b), and the low-viscosity PLLA at $190^{\circ} \mathrm{C}$ deformed more and formed thinner lamellae (Fig. 3c and d). The formation of lamellar structures in miscible polymer blends go through repetitive thinning to fine lamellae until molecular diffusion takes over and homogenizes the system [39].

The higher magnification SEM images in Fig. 4a-d show the representative microstructures of lamellar scaffolds originating from different processing conditions. The sizes of the micropores ranged from less than $1 \mu \mathrm{m}$ down to the nanometer scale. The number of micropores observed on the lamellae (Fig. 4a and b) from low melt processing temperatures are higher compared with the 

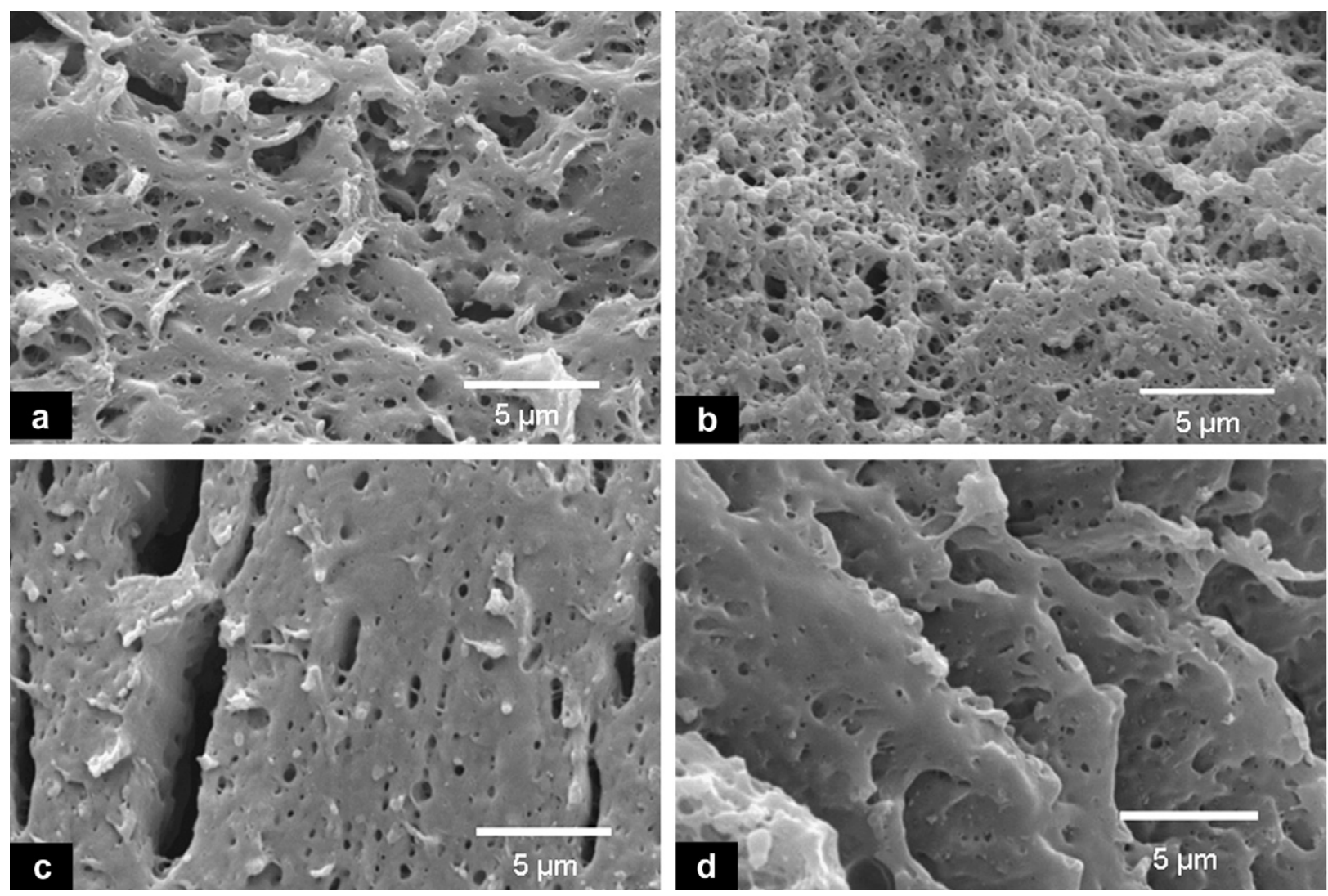

Fig. 4. Higher-magnification SEM micrographs showing the micropores on lamellae of PLLA scaffolds prepared from injection molding of a 50/50 wt. $\%$ blend of PLLA and PEO followed by swelling and posterior leaching of porogen. (a) Melt processing temperature $=165^{\circ} \mathrm{C}$, injection flow rate $=7$ $\mathrm{cm}^{3} \mathrm{~s}^{-1}$; (b) melt processing temperature $=165^{\circ} \mathrm{C}$, injection flow rate $=56 \mathrm{~cm}^{3} \mathrm{~s}^{-1}$; (c) melt processing temperature $=190^{\circ} \mathrm{C}$, injection flow rate $=7$ $\mathrm{cm}^{3} \mathrm{~s}^{-1}$; (d) melt processing temperature $=190^{\circ} \mathrm{C}$, injection flow rate $=56 \mathrm{~cm}^{3} \mathrm{~s}^{-1}$.

number of micropores from high melt processing temperature conditions (Fig. 4c and d). The micropores on the lamellae are spherical with low melt processing temperatures and more elongated with high melt processing temperatures.

Typically, the injection molded specimens exhibit a skin-core structure with different microstructures in skin and core [41]. In contrast to the skin-core structures of injection molding, the low-magnification SEM micrograph in Fig. 5 shows an interesting porous PLLA architecture resulting from injection molding of 50/50 wt.\% PLLA and PEO blend followed by swelling and leaching of PEO. The distribution of lamellae across the cross-section is uniform. This even distribution of lamellae clearly undermines the effect of the rheological parameters of injection molding on morphological development of 50/50 wt.\% PLLA/PEO blend.

As the aim of this work was to produce porous scaffolds, it is important to understand the mechanism of pore formation in the layered structures.

\subsection{Swelling behavior and leaching of porogen}

Without increasing the porogen fraction, the porosity of a scaffold can be increased by swelling, giving an additional

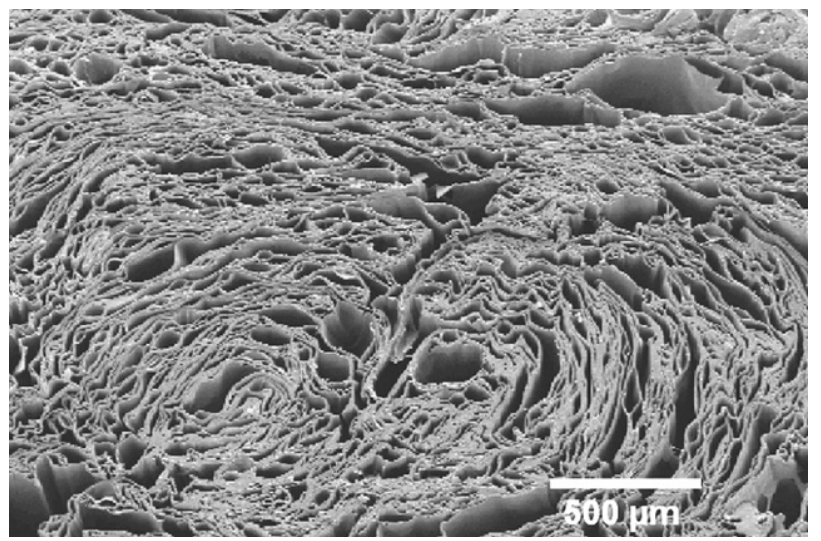

Fig. 5. Low-magnification SEM photographs along the cross-section of a porous PLLA scaffold showing the uniform lamellar architecture produced with a melt processing temperature of $190{ }^{\circ} \mathrm{C}$ and an injection flow rate of $7 \mathrm{~cm}^{3} \mathrm{~s}^{-1}$. This homogeneous lamellar structure is in contrast to heterogeneous skin-core structure of conventional injection molding.

degree of freedom in the scaffold design. After ejection from the mold, the specimens were immediately put in water at $37^{\circ} \mathrm{C}$. Fig. 6 shows the equilibrium swelling of injected specimens produced with different processing conditions. The average degree of swelling of the specimens produced with runs $\mathrm{C} 1, \mathrm{C} 2, \mathrm{C} 3$ and $\mathrm{C} 4$ were $58 \%, 25 \%$, 


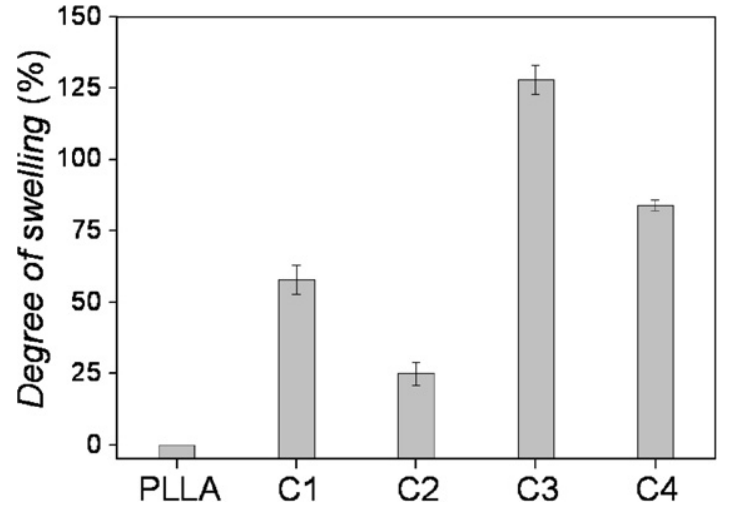

Fig. 6. Degree of swelling of a 50/50 wt.\% blend of PLLA and PEO in water at $37^{\circ} \mathrm{C}$ for specimens with different lamellar structures. Compact PLLA specimens were used as reference.

$128 \%$ and $84 \%$, respectively, while pure PLLA specimens did not swell significantly, as expected.

The results indicate that the degree of swelling is directly related to the morphology that develops during processing. The specimens with low melt processing temperature (runs $\mathrm{C} 1$ and $\mathrm{C} 2$ ) demonstrate a lower degree of swelling, and the specimens with high melt processing temperature (runs C3 and C4) exhibit a higher degree of swelling. Moreover, under both temperature regimes, the increase of injection flow rate (from $\mathrm{C} 1$ to $\mathrm{C} 2$ and $\mathrm{C} 3$ to $\mathrm{C} 4$ ) decreased the degree of swelling. It seems that the degree of swelling increases with the increasing number of lamellae (Fig. 3c and d) and decreases with increasing lamellar thickness (Fig. 3a and b).

The swelling and leaching of the PEO-rich layer produces the lamellar macropores (Fig. 3a-d). The leaching of phase-separated PEO from the initially homogeneous PLLA/PEO phase produces micropores on the PLLA lamellae (Fig. 4a-d). The micropores created by this technique may play an important role in regulating cell behavior [42]. In general, micro- and nano-textures can be created on polymeric substrates by other nanofabrication techniques $[43,44]$. In this study, the micropores created by dissolution of PEO may be useful for enhancing cellsubstrate interaction [45].

\subsection{Porosity and water uptake}

Fig. 7 shows the porosity and water uptake capabilities of the macroporous PLLA scaffolds prepared with different injection moldingprocessing conditions followed by swelling and leaching of porogen. The scaffolds prepared from high melt processing temperature conditions ( $\mathrm{C} 3$ and $\mathrm{C} 4)$ exhibit higher porosities compared to the scaffolds prepared from low melt temperature conditions $(\mathrm{C} 1$ and $\mathrm{C} 2$ ). The residual amount of PEO in the scaffolds prepared from $\mathrm{C} 1, \mathrm{C} 2, \mathrm{C} 3$ and $\mathrm{C} 4$ were 25, 22, 9 and $10 \mathrm{wt} . \%$, respectively, while the added amount of PEO was $50 \mathrm{wt} . \%$. The amount of PEO in the porous construct could not be calculated quantitatively by differential scanning

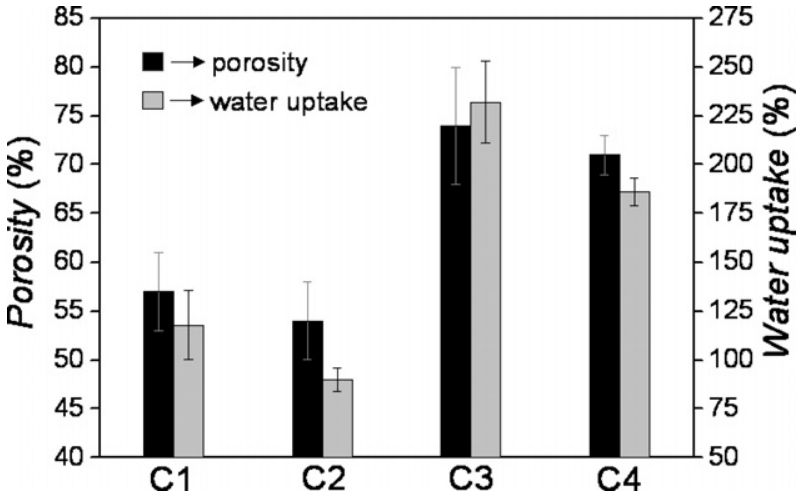

Fig. 7. Porosity and water uptake of porous lamellar PLLA porous constructs obtained from different injection molding conditions followed by posterior leaching of porogen.

calorimetry (DSC) as the PLLA glass transition temperature $\left(61^{\circ} \mathrm{C}\right)$ and PEO melting temperature $\left(58^{\circ} \mathrm{C}\right)$ are close [33]. The residual amount of PEO was calculated assuming that the mass loss was solely due to dissolution of PEO [46]. The extent of dissolution of PEO was directly related to the thicknesses of lamellae. A lower fraction of PEO was trapped in the scaffolds with thinner lamellae (C3 and C4), whereas a higher fraction of PEO was trapped in the thicker lamellae $(\mathrm{C} 1$ and $\mathrm{C} 2)$. The average porosities of $\mathrm{C} 1, \mathrm{C} 2, \mathrm{C} 3$ and $\mathrm{C} 4$ were $57 \pm 4,54 \pm 4,74 \pm 6$ and $71 \pm 2 \%$, respectively. The observed porosities are quantitatively higher than the leached PEO fraction as additional void volume was created by swelling. However, the porosities were underestimated as the wet scaffolds shrank upon drying, and the average shrinkages of $\mathrm{C} 1, \mathrm{C} 2, \mathrm{C} 3$ and $\mathrm{C} 4$ were $10 \%, 8 \%, 30 \%$ and $23 \%$, respectively.

The water uptake followed exactly the same trend as the porosity. The average water uptake of $\mathrm{C} 1, \mathrm{C} 2, \mathrm{C} 3$ and $\mathrm{C} 4$ were $118 \%, 90 \%, 232 \%$ and $186 \%$, respectively (Fig. 7). The scaffolds prepared with $T_{\mathrm{m}}=190^{\circ} \mathrm{C}(\mathrm{C} 3$ and C4) had higher water uptake compared with those from $T_{\mathrm{m}}=165^{\circ} \mathrm{C}(\mathrm{C} 1$ and $\mathrm{C} 2)$. Moreover, water uptake of the "C3 and $\mathrm{C} 4$ scaffolds" compared with the " $\mathrm{C} 1$ and $\mathrm{C} 2$ scaffolds" is proportionally higher than the increment in porosity. The similar trend of proportionally higher water uptake compared with the increment of porosity was also observed in isotropic porous scaffolds [47]. The increase in the number of channels increases the surface area of such multitubular architectures [15]. This increased surface area could improve the cell-seeding efficiency and cell-attachment propertied of these oriented scaffolds [43].

\subsection{Mechanical properties}

An important requirement for most tissue engineering constructs is to match the mechanical properties of the host tissue and implant, until the regenerated tissue takes over the load-bearing function. Fig. 8a shows the tensile moduli of the four different scaffolds prepared with four distinct processing conditions. The highest and lowest values of 

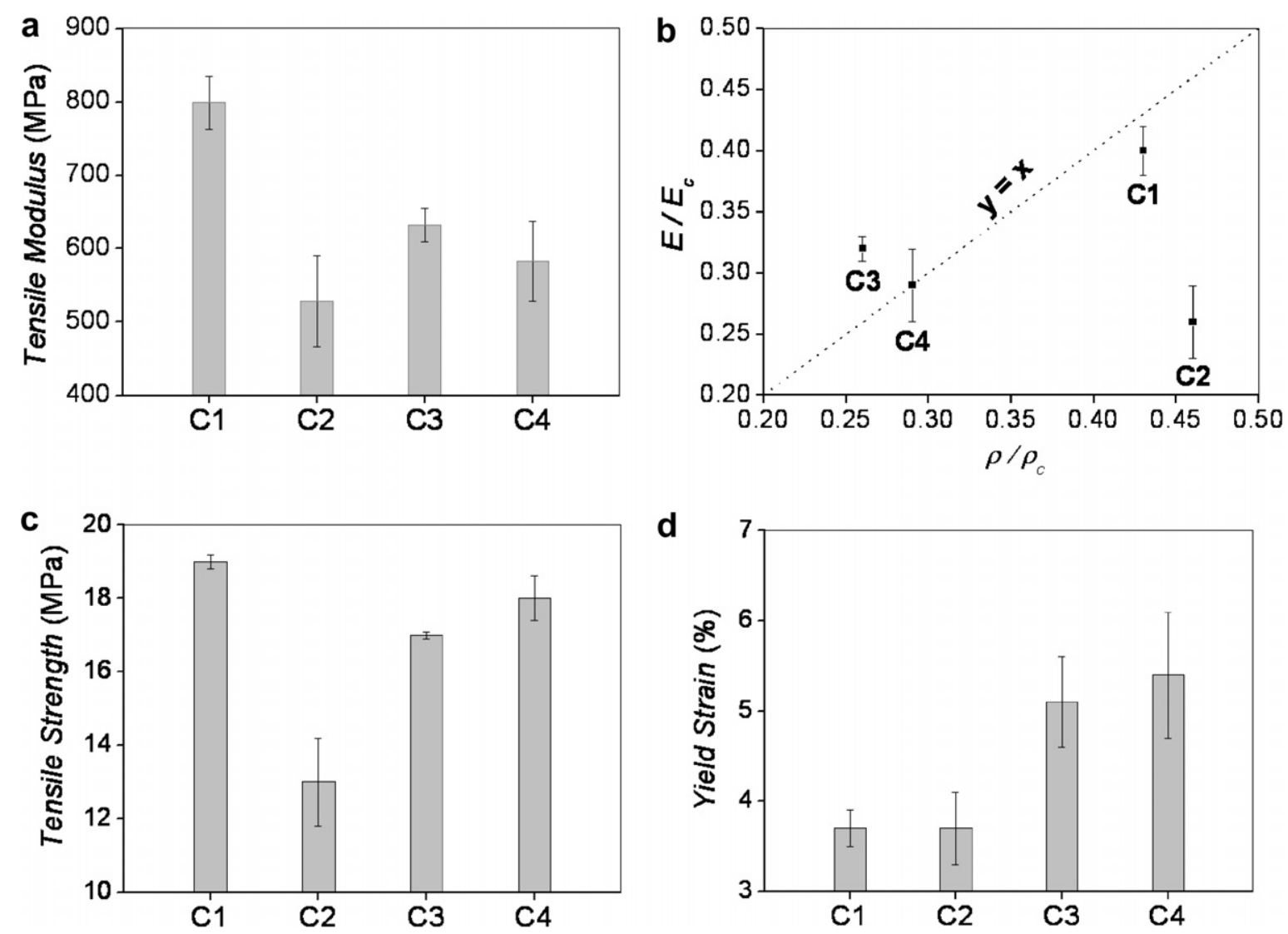

Fig. 8. Effect of different lamellar structures and porosities on (a) tensile moduli, (c) tensile strength and (d) yield strain of oriented porous scaffolds originating from different injection molding conditions of 50/50 wt.\% PLLA and PEO blend followed by swelling and posterior leaching of porogen; (b) normalized modulus as a function of normalized density. Dotted line shows theoretical relationship of Voigt model, where normalized modulus $(y)=$ normalized density $(x)$.

moduli are 799 and $528 \mathrm{MPa}$, respectively (a variation of $51 \%$ due to processing). As the modulus of a porous scaffold is related to the modulus of parent polymer and porosity, it is reasonable to compare the normalized modulus (ratio of porous scaffold modulus to compact polymer modulus) with the normalized density (ratio of porous scaffold density to compact density) [48]. Fig. 8b shows the normalized modulus as a function of normalized density. There are several models to describe the mechanical property-porosity relationship of different porous constructs with simplified assumptions. The Voigt model given by Eq. (4) can be used to relate the tensile modulus to the density of these unidirectionally oriented porous scaffolds [48]

$\frac{E}{E_{c}}=(1-f)=\frac{\rho}{\rho_{\mathrm{c}}}$,

where $E$ and $\rho$ are the apparent elastic moduli and apparent densities of porous scaffolds, respectively, and $f$ is the void fraction of the scaffold. The average elastic modulus $\left(E_{c}\right)$ of PLLA is taken as $2.0 \mathrm{GPa}$ [34] and the compact density $\left(\rho_{\mathrm{c}}\right)$ of PLLA as $1248 \mathrm{~kg} \mathrm{~m}^{-3}$ [35]. As per the Voigt model, the dotted line in Fig. $8 \mathrm{~b}$ shows the theoretical relationship between normalized modulus and normalized density. The normalized moduli of $\mathrm{C} 1, \mathrm{C} 3$ and $\mathrm{C} 4$ fit nearly to the normalized density. However, the tensile modulus of
C2 has a lower value than the theoretically predicted value. A possible reason for this discrepancy could be related to the uneven lamellae of $\mathrm{C} 2$ - see Fig. 3b. This unevenness in lamellar thickness could act as defects which may reduce the modulus of the cellular constructs [49]. For uneven lamellae, the stress concentration in the slender regions of lamellae could result in lower modulus values compared with the theoretically predicted values. It is worth mentioning that the lamellar morphology formed during injection molding was co-continuous in all the processing conditions and was maintained in the PLLA porous constructs. This fitting of normalized tensile moduli with normalized densities in most of the scaffolds can be regarded as a measure of continuity of the lamellae in the porous constructs.

Fig. 8c shows the tensile strength behavior of anisotropic scaffolds originating from different processing conditions. The average tensile strength values for $\mathrm{C} 1, \mathrm{C} 2, \mathrm{C} 3$ and $\mathrm{C} 4$ were $19,13,17$ and $18 \mathrm{MPa}$, respectively, whereas the corresponding porosities were $57 \%, 54 \%, 74 \%$ and $71 \%$, respectively. Similar to modulus, the defects in the lamellae of $\mathrm{C} 2$ reduce the tensile strength. Excluding $\mathrm{C} 2$, the results indicate that the variation in porosity $(\mathrm{Cl}, \mathrm{C} 3$ and $\mathrm{C} 4)$ had little influence on the tensile strength of the scaffolds. Fig. $8 \mathrm{~d}$ shows the tensile yield strain of the oriented porous scaffolds obtained by different injection molding processing 
conditions. The results show that the yield strain values are directly related to porosity, as $\mathrm{C} 1$ and $\mathrm{C} 2$, with low porosities, show low yield strain, whereas $\mathrm{C} 3$ and $\mathrm{C} 4$, with higher porosities, exhibit higher yield strain. Low melt processing temperature conditions give rise to lower yield strain, and high melt processing temperature conditions produce higher yield strain. The results indicate that the yield strain increases with increasing numbers of lamellae in the scaffolds. Therefore, the injection moldingprocessing parameters could control the lamellar blend morphology of partially miscible and biphasic PLLA/PEO blend. Upon swelling and leaching of porogen, the mechanical property and porosity could be then tailored for desired medical or tissue engineering applications.

\section{Conclusions}

A novel technique for the fabrication of porous lamellar PLLA scaffolds was developed using conventional injection molding of a 50/50 wt.\% blend of PLLA and PEO followed by swelling and selective porogen leaching. This technique produced porous lamellar scaffolds in which (i) a lamellar architecture with alternate layers of homogeneous PLLA/ PEO phase and PEO-rich phase was developed using injection molding; (ii) the lamellar thickness could be controlled by melt processing temperature; (iii) the macropore sizes and porosities could be controlled by injection moldingprocessing parameters and swelling; (iv) the micropores could be obtained on the pore walls through leaching of phaseseparated PEO from initially homogeneous PLLA/PEO phase.

The rheological parameters are not relevant in regulating the lamellar structure formation of this partially miscible PLLA and PEO blend. The lamellae are integral to all the porous structures irrespective of the injection moldingprocessing conditions used. The melt processing temperature was the most significant parameter affecting the porosity, water uptake and mechanical properties of the lamellar scaffolds. A melt processing temperature of $190{ }^{\circ} \mathrm{C}$ resulted in uniform lamellar architecture with even lamellar thickness, the highest porosity, good mechanical properties, and a low level of residual porogen in the obtained scaffolds.

This processing technique of preparing porous lamellar scaffolds by injection molding, quenching, swelling and leaching of porogen is a simple and reproducible process. Long, anisotropically oriented lamellar scaffolds can be prepared by this methodology. This organic-solvent-free processing technique with superior process controls offers a versatile route for preparing PLLA-based porous scaffolds with lamellar morphology that can be tailored for different tissue engineering applications.

\section{Acknowledgments}

Financial support for this work was provided by FCT, through the POCTI and FEDER programmes, and the project POCTI/FIS/61621/2004. S.G. thanks FCT for the award of a PhD Grant, SFRH/BD/12657/2003. This work was also partially supported by the European Union funded STREP Project HIPPOCRATES (NMP3-CT2003-505758).

\section{References}

[1] Freed LE, Grande DA, Lingbin Z, Emmanual J, Marquis JC, Langer R. Joint resurfacing using allograft chondrocytes and synthetic biodegradable polymer scaffolds. J Biomed Mater Res 1994;28:891-9.

[2] Murphy WL, Kohn DH, Mooney DJ. Growth of continuous bonelike mineral within porous poly(lactide-co-glycolide) scaffolds in vitro. J Biomed Mater Res 2000;50:50-8.

[3] Middleton JC, Tipton AJ. Synthetic biodegradable polymers as orthopedic devices. Biomaterials 2000;21:2335-46.

[4] Chupa JM, Foster AM, Sumner SR, Madihally SV, Matthew HWT. Vascular cell responses to polysaccharide materials: in vitro and in vivo evaluations. Biomaterials 2000;21:2315-22.

[5] Suzuki M, Ikada Y. Biodegradable polymers in medicine. In: Reis RL, San Román J, editors. Biodegradable systems in tissue engineering and regenerative Medicine. New York: CRC Press; 2005. p. 3-12.

[6] Widmer MS et al. Manufacture of porous biodegradable polymer conduits by an extrusion process for guided tissue regeneration. Biomaterials 1998;19:1945-55.

[7] Harley BA, Hastings AZ, Yannas IV, Sannino A. Fabricating tubular scaffolds with a radial pore size gradient by a spinning technique. Biomaterials 2006;27:866-74.

[8] Boccaccini AR, Blaker JJ, Maquet V, Day RM, Jerome R. Preparation and characterisation of poly(lactide-co-glycolide) (PLGA) and PLGA/Bioglass ${ }^{\circledR}$ composite tubular foam scaffolds for tissue engineering applications. Mater Sci Eng C 2005;25:23-31.

[9] Mooney DJ, Mazzoni CL, Breuer C, McNamara K, Hern D, Vacanti JP, et al. Stabilized polyglycolic acid fibre-based tubes for tissue engineering. Biomaterials 1996;17:115-24.

[10] Wang A, Ao Q, Cao W, Yu M, He Q, Kong L, et al. Porous chitosan tubular scaffolds with knitted outer wall and controllable inner structure for nerve tissue engineering. J Biomed Mater Res A 2006;79:36-46.

[11] Ma PX, Zhang R. Microtubular architecture of biodegradable polymer scaffolds. J Biomed Mater Res 2001;56:469-77.

[12] Maquet V, Martin D, Malgrange B, Franzen R, Schoenen J, Moonen $\mathrm{G}$, et al. Peripheral nerve regeneration using bioresorbable macroporous polylactide scaffolds. J Biomed Mater Res 2000;52:639-51.

[13] Stokols S, Tuszynski MH. The fabrication and characterization of linearly oriented nerve guidance scaffolds for spinal cord injury. Biomaterials 2004;25:5839-46.

[14] Moore MJ, Friedman JA, Lewellyn EB, Mantila SM, Krych AJ, Ameenuddin S, et al. Multiple-channel scaffolds to promote spinal cord axon regeneration. Biomaterials 2006;27:419-29.

[15] Sundback C, Hadlock T, Cheney M, Vacanti J. Manufacture of porous polymer nerve conduits by a novel low pressure injection molding process. Biomaterials 2003;24:819-30.

[16] Patist CM, Mulder MB, Gautier SE, Maquet V, Jerome R, Oudega M. Freeze-dried poly(D,L-lactic acid) macroporous guidance scaffolds impregnated with brain-derived neurotrophic factor in the transected adult rat thoracic spinal cord. Biomaterials 2004;25:1569-82.

[17] Maquet V, Martin D, Scholtes F, Franzen R, Schoenen J, Moonen G, et al. Poly(D,L-lactide) foams modified by poly(ethylene oxide)-blockpoly(D,L-lactide) copolymers and a-FGF: in vitro and in vivo evaluation for spinal cord regeneration. Biomaterials 2001;22: $1137-46$.

[18] Schoof H, Apel J, Heschel I, Rau G. Control of pore structure and size in freeze-dried collagen sponges. $J$ Biomed Mater Res 2001;58:352-7. 
[19] Flynn L, Dalton PD, Shoichet MS. Fiber templating of poly(2hydroxyethyl methacrylate) for neural tissue engineering. Biomaterials 2003;24:4265-72.

[20] Yu TT, Shoichet MS. Guided cell adhesion and outgrowth in peptidemodified channels for neural tissue engineering. Biomaterials 2005;26:1507-14.

[21] Silva MMCG, Cyster LA, Barry JJA, Yang XB, Oreffo ROC, Grant $\mathrm{DM}$, et al. The effect of anisotropic architecture on cell and tissue infiltration into tissue engineering scaffolds. Biomaterials 2006;27:5909-17.

[22] Lin ASP, Barrows TH, Cartmell SH, Guldberg RE. Microarchitectural and mechanical characterization of oriented porous polymer scaffolds. Biomaterials 2003;24:481-9.

[23] Forman S, Kas J, Fini F, Steinberg M, Ruml T. The effect of different solvents on the ATP/ADP content and growth properties of HeLa cells. J Biochem Mol Toxic 1999;13:11-5.

[24] Washburn NR, Simon Jr CG, Tona A, Elgendy HM, Karim A, Amis EJ. Co-extrusion of biocompatible polymers for scaffolds with cocontinuous morphology. J Biomed Mater Res 2002;60:20-9.

[25] Sarazin P, Roy X, Favis BD. Controlled preparation and properties of porous poly(L-lactide) obtained from a co-continuous blend of two biodegradable polymers. Biomaterials 2004;25:5965-78.

[26] Yuan Z, Favis BD. Macroporous poly(L-lactide) of controlled pore size derived from the annealing of co-continuous polystyrene/poly(Llactide) blends. Biomaterials 2004;25:2161-70.

[27] Lee HS, Kim ES. Linear viscoelasticity and the measurement of interfacial tension in a partially miscible polymer mixture. Macromolecules 2005;38:1196-200.

[28] Gomes ME, Ribeiro AS, Malafaya PB, Reis RL, Cunha AM. A new approach based on injection moulding to produce biodegradable starch-based polymeric scaffolds: morphology, mechanical and degradation behaviour. Biomaterials 2001;22:883-9.

[29] Peppas NA, Keys KB, Torres-Lugo M, Lowman AM. Poly(ethylene glycol)-containing hydrogels in drug delivery. J Control Release 1999;62:81-7.

[30] Koning C, Van Duin M, Pagnoulle C, Jerome R. Strategies for compatibilization of polymer blends. Prog Polym Sci 1998;23:707-57.

[31] Meaurio E, Zuza E, Sarasua JR. Miscibility and specific interactions in blends of poly(L-lactide) with poly(vinylphenol). Macromolecules 2005;38:1207-15.

[32] Brandrup J, Immergut EH. Polymer handbook. New York: Wiley; 1989 , p. 555.

[33] Nijenhuis AJ, Colstee E, Grijpma DW, Pennings AJ. High molecular weight poly(L-lactide) and poly(ethylene oxide) blends: thermal characterization and physical properties. Polymer 1996;37:5849-57.

[34] Ghosh S, Viana JC, Reis RL, Mano JF. Effect of processing conditions on morphology and mechanical properties of injection molded poly(L-lactic acid). Polym Eng Sci 2007;47:1141-7.
[35] Shin D, Shin K, Aamer KA, Tew GN, Russell TP, Lee JH, et al. A morphological study of a semicrystalline poly(L-lactic acid-b-ethylene oxide-b-L-lactic acid) triblock copolymer. Macromolecules 2005;38: $104-9$.

[36] Cooper-White JJ, Mackay ME. Rheological properties of poly (iactides) Effect of molecular weight and temperature on the viscoelasticity of poly (L-lactic acid). J Polym Sci, Part B: Polym Phys 1999;37:1803-14.

[37] Ghosh S, Viana JC, Reis RL, Mano JF. The double porogen approach as a new technique for the fabrication of interconnected poly(L-lactic acid) and starch based biodegradable scaffolds. J Mater Sci Mater Med 2007;18:185-93.

[38] Utracki LA, Shi GZH. Compounding polymer blends. In: Utracki LA, editor. Polymer blends handbook. Dordrecht: Kluwer; 2002. p. $577-651$.

[39] Jana SC, Sau M. Effects of viscosity ratio and composition on development of morphology in chaotic mixing of polymers. Polymer 2004;45:1665-78.

[40] Dhoble A, Kulshreshtha B, Ramaswami S, Zumbrunnen DA. Mechanical properties of PP-LDPE blends with novel morphologies produced with a continuous chaotic advection blender. Polymer 2005;46:2244-56.

[41] Viana JC, Cunha AM, Billon N. The thermomechanical environment and the microstructure of an injection moulded polypropylene copolymer. Polymer 2002;43:4185-96.

[42] Flemming RG, Murphy CJ, Abrams GA, Goodman SL, Nealey PF. Effects of synthetic micro- and nano-structured surfaces on cell behavior. Biomaterials 1999;20:573-88.

[43] Recknor JB, Sakaguchi DS, Mallapragada SK. Directed growth and selective differentiation of neural progenitor cells on micropatterned polymer substrates. Biomaterials 2006;27:4098-108.

[44] Gates BD, Xu Q, Stewart M, Ryan D, Wilson CG, Whitesides GM. New approaches to nanofabrication: molding, printing and other techniques. Chem Rev 2005;105:1171-96.

[45] Wan Y, Wang Y, Liu Z, Qu X, Han B, Bei J, et al. Adhesion and proliferation of OCT-1 osteoblast-like cells on micro- and nano-scale topography structured poly(L-lactide). Biomaterials 2005;26:4453-9.

[46] Tsuji H, Smith R, Bonfield W, Ikada Y. Porous biodegradable polyesters. I. Preparation of porous poly (L-lactide) films by extraction of poly(ethylene oxide) from their blends. J Appl Polym Sci 2000;75:629-37.

[47] Ghosh S et al. Dynamic mechanical behavior of starch-based scaffolds in dry and physiologically simulated conditions: effect of porosity and pore size. Acta Biomater 2008;4:950-9.

[48] Zhang Y, Rodrigue D, Ait-Kadi A. High density polyethylene foams. II. Elastic modulus. J Appl Polym Sci 2003;90:2120-9.

[49] Grenestedt JL. Influence of wavy imperfections in cell walls on elastic stiffness of cellular solids. J Mech Phys Solids 1998;46:29-50. 